\title{
The Standardized Nordic Questionnaire Applied to Workers Exposed to Hand-Arm Vibration
}

\author{
Orawan Kaewboonchoo ${ }^{1}$, Hiroichi Yamamoto ${ }^{1}$, Nobuyuki Mryal ${ }^{1}$, \\ Seyed Mohamad Mirbod ${ }^{2}$, Ikuharu Morioka ${ }^{1}$ and Kazuhisa Miyashita ${ }^{1}$ \\ ${ }^{1}$ Department of Hygiene, School of Medicine, Wakayama Medical University and \\ ${ }^{2}$ Department of Hygiene, School of Medicine, Gifu University
}

\begin{abstract}
The Standardized Nordic Questionnaire Applied to Workers Exposed to Hand-Arm Vibration: Orawan KaEwBOONCHOO, et al. Department of Hygiene, School of Medicine, Wakayama Medical UniversityThe standardized Nordic questionnaire (SNQ) is not yet widely used in Japan. This paper describes the possibility whether the SNQ, translated into Japanese, can be applied to workers exposed to hand-arm vibration. The musculoskeletal symptoms of 40 chain saw operators (CS) in private forests and 40 agematched bush cleaner operators $(B C)$ in the public service sector were assessed by the SNQ and the Japanese questionnaire (JQ). Both the SNQ and the $J Q$ showed that $C S$ had a higher prevalence of symptoms than $B C$. By the SNQ, there were significant differences in the prevalence of musculoskeletal symptom in the elbows, upper back and knees. By the $J Q, C S$ had significantly higher prevalence of pain in the shoulders and elbows than $\mathrm{BC}$. These results show the SNQ also fits the musculoskeletal symptoms and clearly differentiates between the prevalences in the two groups. The SNQ enables us to identify the severity, the duration, the treatment and the disability, but does not include items related to finger numbness and finger blanching. For that reason some JQ items should be applied to workers exposed to hand-arm vibration.

(J Occup Health 1998; 40: 218-222)
\end{abstract}

Key words: Standardized Nordic questionnaire, Handarm vibration, Musculoskeletal symptoms, Vibration syndrome

Prolonged exposure to hand-arm vibration can give rise to musculoskeletal disorders of the hand-arm, as well as neurological or vascular disorders. Musculoskeletal disorders are the initial or secondary symptom of the

Received Sept 29, 1997; Accepted Apr 21, 1998

Correspondence to: $O$. Kaewbonchoo, Department of Hygiene, School of Medicine, Wakayama Medical University, 811-1 Kimiidera, Wakayama 641-0012, Japan hand-arm disorders caused by hand-arm vibration"). They are therefore important symptom for health surveillance. One of the most popular survey tools for detecting musculoskeletal disorders is the standardized Nordic questionnaire (SNQ). The SNQ was developed by a team of Nordic researchers organized to create a simple standardized questionnaire that could be used for the screening of musculoskeletal disorders as a part of ergonomic programs and for epidemiological studies of musculoskeletal disorders ${ }^{2)}$. But the SNQ is not yet widely used in Japan, particular in workers exposed to hand-arm vibration.

This paper outlines the possibility whether the SNQ, translated into Japanese, can be applied to workers exposed to hand-arm vibration.

\section{Subjects and Methods}

The subjects of this study were 40 male chain saw operators (CS) in private forests and 40 male age-matched bush cleaner operators (BC) in the public service sector in Wakayama Prefecture, Japan. The subjects' age ranged between 22 and 71 years. Mean age of $\mathrm{CS}$ and $\mathrm{BC}$ was $50 \pm 14$ years and $51 \pm 15$ years, respectively. Their mean length of the job experience was $20 \pm 16$ years in $\mathrm{CS}$ and $21 \pm 12$ years in $\mathrm{BC}$.

The SNQ was translated into Japanese with cross checking. Physicians asked the subjects to assess musculoskeletal disorders by using the SNQ. It originally consists of a general questionnaire and a more detailed body part-specific questionnaire. The general questionnaire shows a body map diagram divided into nine anatomic regions and asks about the presence of physical troubles including ache, pain, discomfort etc., for the past 12 months and past 7 days in each of the body areas. It also includes grades of severity by using a measure of functional status: "Have you at any time during the last 12 months been prevented from doing your normal work (at home or away from home) because of 
Table 1. Prevalence of pain in $\mathrm{CS}$ and $\mathrm{BC}$ by JQ

\begin{tabular}{lcc}
\hline Body parts & $\begin{array}{c}\mathrm{CS} \\
(\mathrm{n}=40)\end{array}$ & $\begin{array}{c}\mathrm{BC} \\
(\mathrm{n}=40)\end{array}$ \\
\hline neck & $1(3)$ & $1(3)$ \\
shoulders & $15(38)^{* *}$ & $3(8)$ \\
elbows & $7(18)^{*}$ & $1(3)$ \\
wrists/hands & $5(13)$ & $3(8)$ \\
upper back & $0(0)$ & $0(0)$ \\
low back & $8(20)$ & $4(10)$ \\
hips/thighs & $0(0)$ & $0(0)$ \\
knees & $2(5)$ & $1(3)$ \\
ankles/feet & $1(3)$ & $2(5)$ \\
\hline
\end{tabular}

Percentage (\%) given in parentheses. ${ }^{*} \mathrm{p}<0.01$, ${ }^{*} \mathrm{p}<0.05$. CS: Chain saw operators. BC: Bush cleaner operators. JQ: Japanese questionnaire.

Table 2. Prevalence of 12-month and 7-day musculoskeletal symptoms in CS and BC by SNQ

\begin{tabular}{lccccc}
\hline \multirow{2}{*}{ Body parts } & \multicolumn{2}{c}{12 -month } & & \multicolumn{2}{c}{7 -day } \\
\cline { 2 - 3 } \cline { 5 - 6 } & $\mathrm{CS}$ & $\mathrm{BC}$ & & $\mathrm{CS}$ & $\mathrm{BC}$ \\
& $(\mathrm{n}=40)$ & $(\mathrm{n}=40)$ & & $(\mathrm{n}=40)$ & $(\mathrm{n}=40)$ \\
\hline neck & $10(25)$ & $4(10)$ & & $7(10)^{*}$ & $1(3)$ \\
shoulders & $20(50)$ & $16(40)$ & & $13(33)^{*}$ & $4(10)$ \\
elbows & $9(23)^{* *}$ & $1(3)$ & & $6(15)^{*}$ & $0(0)$ \\
wrists/hands & $4(10)$ & $1(3)$ & & $0(0)$ & $1(3)$ \\
upper back & $6(15)^{*}$ & $0(0)$ & & $1(3)$ & $0(0)$ \\
low back & $24(60)$ & $16(40)$ & & $8(20)$ & $3(8)$ \\
hips/thighs & $1(3)$ & $2(5)$ & & $0(0)$ & $1(3)$ \\
knees & $8(20)^{*}$ & $2(5)$ & & $1(3)$ & $2(5)$ \\
ankles/feet & $2(5)$ & $4(10)$ & & $1(3)$ & $2(5)$ \\
\hline
\end{tabular}

Percentage $(\%)$ given in parentheses. ${ }^{* *} \mathrm{p}<0.01,{ }^{*} \mathrm{p}<0.05$. CS: Chain saw operators. BC: Bush cleaner operators. SNQ: Standardized Nordic questionnaire.

the trouble?" All answers are in the form of a dichotomous yes/no response. It took about $5 \mathrm{~min}$ to fill out the questionnaire.

Before the SNQ was carried out, all subjects were asked to answer the questions in the Japanese questionnaire (JQ) by self-administration. It took about 2 min to fill out the questionnaire. The JQ has been used to screen musculoskeletal disorders in workers exposed to handarm vibration in Japan (Appendix Table). This shows a body part diagram and asks about the prevalence of symptoms with a question: "Have you at anytime had pain in any parts of your body? ....yes ....no; if yes, please fill in the areas in the part of your body in which you have had pain". It also includes questions on duration, time of onset and severity as well as the symptoms of
Table 3. Prevalence of sick leave in CS and BC by $\mathrm{SNQ}$

\begin{tabular}{lcc}
\hline Body parts & $\begin{array}{c}\text { CS } \\
(\mathrm{n}=40)\end{array}$ & $\begin{array}{c}\mathrm{BC} \\
(\mathrm{n}=40)\end{array}$ \\
\hdashline neck & $0(0)$ & $0(0)$ \\
shoulders & $3(8)$ & $0(0)$ \\
elbows & $3(8)$ & $0(0)$ \\
wrists/hands & $1(3)$ & $0(0)$ \\
upper back & $1(3)$ & $0(0)$ \\
low back & $5(13)$ & $1(3)$ \\
hips/thighs & $1(3)$ & $0(0)$ \\
knees & $1(3)$ & $1(3)$ \\
ankles/feet & $1(3)$ & $0(0)$ \\
\hline
\end{tabular}

Percentage $(\%)$ given in parentheses. CS: Chain saw operators. BC: Bush cleaner operators. SNQ: Standardized Nordic questionnaire.

finger numbness and finger blanching.

The chi square test was used to analyze the difference in prevalence between $\mathrm{CS}$ and $\mathrm{BC}$.

\section{Results}

\section{The results of the $J Q$}

The prevalences of pain are shown in Table 1. On the whole, $\mathrm{CS}$ had a higher prevalence of pain than $\mathrm{BC}$. There were significant differences between prevalences of pain in the shoulders and elbows.

\section{The results of the $S N Q$}

The prevalences of 12-month and 7-day musculoskeletal symptoms are shown in Table 2 . On the whole, the prevalences were higher in CS than in BC. Among the 12-month musculoskeletal symptoms, CS had a significantly higher prevalence in the elbows, upper back and knees than BC. Among the 7-day musculoskeletal symptoms, CS had significantly higher prevalence in the neck, shoulders and elbows than $\mathrm{BC}$.

The prevalence of sick leave because of musculoskeletal symptoms in CS was not significantly higher than in BC (Table 3).

No difference was observed between $\mathrm{CS}$ and $\mathrm{BC}$ in the number of operators who had changed jobs, reduced work activity and leisure activity and who had been hospitalized because of musculoskeletal symptoms, but the number of operators who had seen a physician because of lower back and shoulders troubles was significant larger in CS than in BC (Table 4).

The prevalence of musculoskeletal symptoms in the lower back, neck and shoulders for more than 30 days was found to be higher in CS than in BC (Table 5). The CS experienced such trouble with low back, neck or shoulder pain by which they were unable to carry out 
Table 4. Severity of troubles in low back, neck, or shoulders in CS and BC by SNQ

\begin{tabular}{|c|c|c|c|c|c|c|}
\hline \multirow[t]{2}{*}{ Severity } & \multicolumn{2}{|c|}{$\begin{array}{c}\text { Low back } \\
\text { troubles }\end{array}$} & \multicolumn{2}{|c|}{$\begin{array}{l}\text { Shoulders } \\
\text { troubles }\end{array}$} & \multicolumn{2}{|c|}{$\begin{array}{c}\text { Neck } \\
\text { troubles }\end{array}$} \\
\hline & $\begin{array}{c}C S \\
(n=40)\end{array}$ & $\begin{array}{c}B C \\
(n=40)\end{array}$ & $\begin{array}{c}C S \\
(n=40)\end{array}$ & $\begin{array}{c}\text { BC } \\
(n=40)\end{array}$ & $\begin{array}{c}C S \\
(n=40)\end{array}$ & $\begin{array}{c}\mathrm{BC} \\
(n=40)\end{array}$ \\
\hline has seen doctor & $9(23)^{*}$ & $2(5)$ & $13(33)^{*}$ & $4(10)$ & $3(8)$ & $1(3)$ \\
\hline reduced leisure activity & $1(3)$ & $1(3)$ & $0(0)$ & $1(3)$ & $0(0)$ & $0(0)$ \\
\hline reduced work activity & $2(5)$ & ] (3) & $1(3)$ & $0(0)$ & $0(0)$ & $0(0)$ \\
\hline hospitalized & $2(5)$ & $5(13)$ & NV & NV & NV & NV \\
\hline changed jobs & $0(0)$ & $1(3)$ & $0(0)$ & $0(0)$ & $0(0)$ & $0(0)$ \\
\hline
\end{tabular}

Percentage (\%) given in parentheses. ${ }^{*} \mathrm{p}<0.05$. CS: Chain saw operators. BC: Bush cleaner operators. NV: Not available. SNQ: Standardized Nordic questionnaire.

Table 5. Prevalence of troubles in lower back, neck, or shoulders for 0-30 days and more than 30 days in CS and BC by SNQ

\begin{tabular}{|c|c|c|c|c|c|c|}
\hline & \multicolumn{2}{|c|}{$\begin{array}{c}\text { Low back } \\
\text { troubles }\end{array}$} & \multicolumn{2}{|c|}{$\begin{array}{c}\text { Shoulders } \\
\text { troubles }\end{array}$} & \multicolumn{2}{|c|}{$\begin{array}{c}\text { Neck pain } \\
\text { troubles }\end{array}$} \\
\hline & $\begin{array}{c}C S \\
(n=32)\end{array}$ & $\begin{array}{c}\text { BC } \\
(n=25)\end{array}$ & $\begin{array}{c}C S \\
(n=22)\end{array}$ & $\begin{array}{c}\text { BC } \\
(n=15)\end{array}$ & $\begin{array}{c}C S \\
(n=12)\end{array}$ & $\begin{array}{c}\text { BC } \\
(n=5)\end{array}$ \\
\hline $0-30$ days & $19(59)$ & $21(84)$ & $8(36)$ & $10(67)$ & $6(50)$ & $3(60)$ \\
\hline more than 30 days & $13(41)^{*}$ & $4(16)$ & $14(64)^{*}$ & $5(33)$ & $6(50)$ & $2(40)$ \\
\hline
\end{tabular}

Percentage (\%) given in parentheses. ${ }^{*} p<0.05$. CS: Chain saw operators. BC: Bush cleaner operators. SNQ: Standardized Nordic questionnaire.

Table 6. Responses to the question "What is the total length of time that troubles in lower back, neck, or shoulders have prevented you from doing your normal work (at home or away from home) during the last 12 months?" in CS and BC by SNQ

\begin{tabular}{|c|c|c|c|c|c|c|}
\hline & \multicolumn{2}{|c|}{$\begin{array}{c}\text { Low back } \\
\text { troubles }\end{array}$} & \multicolumn{2}{|c|}{$\begin{array}{c}\text { Shoulders } \\
\text { troubles }\end{array}$} & \multicolumn{2}{|c|}{$\begin{array}{c}\text { Neck } \\
\text { troubles }\end{array}$} \\
\hline & $\begin{array}{c}C S \\
(n=23)\end{array}$ & $\begin{array}{c}\text { BC } \\
(n=15)\end{array}$ & $\begin{array}{c}C S \\
(n=20)\end{array}$ & $\begin{array}{c}B C \\
(n=14)\end{array}$ & $\begin{array}{c}C S \\
(n=10)\end{array}$ & $\begin{array}{c}\text { BC } \\
(n=4)\end{array}$ \\
\hline 0 days & $18(78)$ & $15(100)$ & $15(75)$ & $14(100)$ & $9(90)$ & $4(100)$ \\
\hline more than 0 days & $5(22)^{*}$ & $0(0)$ & $5(25)^{*}$ & $0(0)$ & $1(10)$ & $0(0)$ \\
\hline
\end{tabular}

Percentage $(\%)$ given in parentheses. ${ }^{*} \mathrm{p}<0.05$. CS: Chain saw operators. $\mathrm{BC}$ : Bush cleaner operators. SNQ: Standardized Nordic questionnaire.

normal work either at home or away from home for one day or more more frequently than $\mathrm{BC}$ (Table 6).

\section{Discussion}

The CS in private forests typically have a longer exposure time to work than the $\mathrm{BC}$ in public service sector. The CS forestry jobs require muscular static activity to carry and operate their chain saws. A chain saw has a higher magnitude of vibration than a bush cleaner, and the operating time of a chain saw is longer.
The CS stand in a bending posture and repeatedly flex and extend their arms, so that the prevalence of musculoskeletal symptoms is higher in CS than in BC.

The JQ differentiated clearly between CS and BC in the prevalence of 2 symptoms. The SNQ also differentiated clearly between $C S$ and $B C$ in the prevalence of 3 symptoms. These results show that the SNQ also fits the musculoskeletal symptoms in workers exposed to hand-arm vibration.

Many researchers have linked the musculoskeletal 
symptoms with exposure time to the work involving repetitive movements and the difference between workloads on individual body segments ${ }^{3-5)}$. Considering the working conditions of $\mathrm{CS}$, musculoskeletal symptoms in the neck, shoulders, elbows, back and knees should be frequent in CS. In this study, by means of the SNQ, the prevalences of 12-month musculoskeletal symptoms in the elbows, upper back and knees were significantly higher in CS than in BC. The prevalences of 7-day musculoskeletal symptoms in the neck, shoulders and elbows were higher in CS. By means of the JQ, the prevalences of pain in the shoulders and elbows were also significantly higher in CS than in $\mathrm{BC}$. These correspond with the results of many studies on workers performing repetitive or sustained static work with their arms and hands ${ }^{6-10)}$.

By means of the SNQ, the prevalences of 12-month musculoskeletal symptom in the shoulders was not significantly different for CS and BC, and that of 7-day musculoskeletal symptom in the shoulders was almost the same as with the JQ. This might be because BC could not recall symptoms in the past, in particular the symptoms of low severity. The prevalence of a symptom depends on its onset and the severity. Recent and more serious symptoms are apt to be remembered more than older and less serious ones ${ }^{21}$.

The SNQ enables us to identify the severity, the duration, the treatment and the disability. The number of operators who had seen a physician because of musculoskeletal symptoms was significantly larger in CS. The prevalence of long-lasting (more than 30 days) lower back, neck and shoulder troubles is higher in CS than in $\mathrm{BC}$. The sick leave rate due to musculoskeletal symptoms was not significantly higher in CS than in BC, but it tends to be higher in CS. Sick leave of one day or more because of low back, neck and shoulder symptoms in CS is also higher than in $\mathrm{BC}$. These results correspond with our hypothesis that the prevalence of musculoskeletal symptoms is higher in $\mathrm{CS}$ than in $\mathrm{BC}$. This information either gives rise to further in-depth investigation or gives hints for decision-making on preventive measures. We can use the SNQ for a follow-up of the effects of improvements in the work environment.

The use of vibration hand tools elicits vibration syndrome including Raynaud phenomenon. Finger numbness is a typical symptom, and is precipitated by exposure to vibration and persists for progressively longer periods of time. Finger blanching is often the next symptom to occur with continued persistent exposure ${ }^{11}$. Early diagnosis is important to prevent the progressive of the disease. In this study, with the JQ, the prevalences of pain, numbness and Raynaud phenomenon were $63 \%$, $57 \%$ and $18 \%$ of the subjects, respectively. The number workers complaining of finger numbness is decreasing ${ }^{12}$, but it is still common, so the symptom of finger numbness is important even now. The SNQ should take some items of the JQ to evaluate the symptoms of finger numbness and finger blanching to apply to workers exposed to handarm vibration. It should contain questions on the duration of the symptoms during the last 12 months. It should also contain questions on severity of the symptoms in terms of their effect on activities at work and during leisure time, and in terms of total duration of symptoms and sick-leave during the preceding 12 months.

\section{References}

1) Matoba $T$, Ishitake T, Kihara $T$. A new criterion proposed for the diagnosis of hand-arm vibration syndrome. Centr Eur J Publ Hlth 1995; 3 suppl: 3739.

2) Kuorinka I, Jonsson B, Kilborn A, et al. Standardized Nordic questionnaire for the analysis of musculoskeletal symptoms. Appl Ergon 1987; 18: 233-237.

3) Jonsson B, Ydreborg B. Identification of ergonomic problems by means of questionnaires for musculoskeletal troubles. In: Brown et al., eds. Proceedings of the $9^{\text {th }}$ Congress of the International Ergonomics association. Boumemouth, 1985: 424-426.

4) Hayashi N, Iijima S, Matsumoto N. A study on influencing factors of the subjective symptoms related with occupational cervicobrachial disorder of female key-operators in latent stage: A path analysis approach. Jpn J Ind Health 1984; 25: 70-76.

5) Maeda K, Hunting W, Grandjean E. Localised fatigue in accounting-machine operators. J Occup Med 1980; 22: $810-816$.

6) Kamwendo K, Linton SJ, Moritz U. Neck and shoulder disorder in medical secretaries, part I: pain prevalence and risk factors. Scand J Rehab Med 1991; 23: 127133.

7) Ohlsson K, Arrewall R, Skerfving S. Self- reported symptoms in the neck and upper limbs of female assembly workers. Scand J Work Environ Health 1989; 15: 75-80.

8) Punnett L, Robins JM, Wegman DH, Keyserling WM. Soft tissue disorders in the upper limbs of female garment workers. Scand J Work Environ Health 1985; 11: $417-425$.

9) Vihma $T$, Nurminen M, Mutanen P. Sewing machine operators' work and musculoskeletal complaints. Ergonomics 1982; 25: 295-298.

10) Hagberg $M$, Wegman DH. Prevalence rates and odds ratios of shoulder-neck diseases in different occupational groups. Br J Ind Med 1987; 44: 602-610.

11) Howard Hu. Other physical hazards and their effects. In: Levy BS, Wegman DH, eds. Occupational Health Recognizing and Preventing Work-Related Disease. Massachusetts: Little, Brown and Company, 1988: 263-280.

12) Miyashita K, Tomida K, Morioka I, Sasaki T, Iwata $H$. Health surveillance of forestry workers exposed to hand-arm vibration in Wakayama from 1974 to 1996. Ind Health 1998; 36: 160-165. 
Appendix table. Questionnaire on subjective symptoms in vibration syndrome

\section{Name.}

Date of birth:

year...... month..........day

Age: years old

Sex: Male / Female

Present address

What do you belong to:

forest association / company / individual/

a fellow worker management / other

1. (past histories of diseases)

2. (past histories of injuries)

3. Have you at any time had numbness, tingling or dullness in the fingers, palms or feet?

(1) yes (2) no

If yes, please answer the following questions.

(I) Please fill in the area in the part of your body in which you have had numbness.
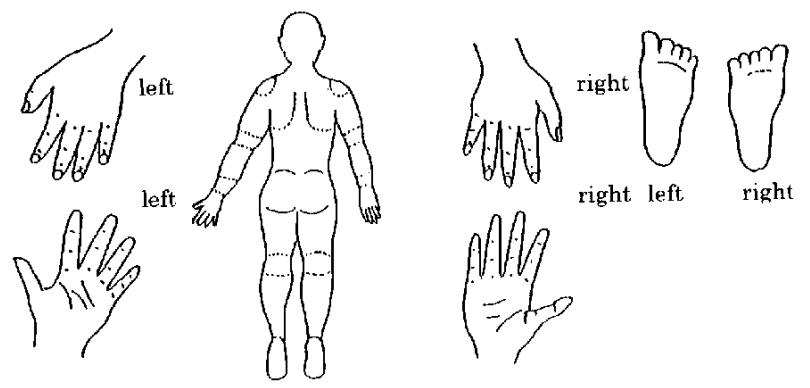

(II) When has it had occurred? years ago)

(III) In which season does it often occur?
a) spring b) summer c) fall d) winter e) any time

(IV) How long does it continue in the season when it often occurs?

a) every day b) several times a week

c) several times a month

d) several times a year

(V) Is it severer than before?
a) severer than before b) no change
c) better than before

4. Have you at any time had white fingers or toes?

(1) yes (2) no

If yes, please answer the following questions.

(I) Please fill in the area in the part of your body in which you have had white fingers or toes.

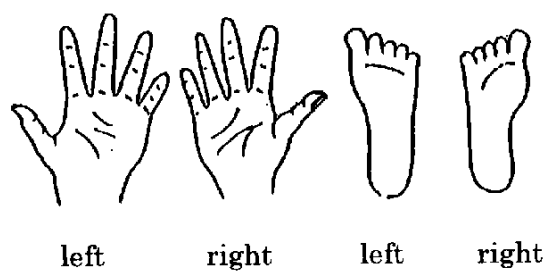

(II) When has it had occurred? (..........years ago)

(III) In which season does it often occur? a) spring b) summer c) fall d) winter e) any time

(IV) How long does it continue in the season when it often occurs?

a) every day b) several times a week

c) several times a month

d) several times a year

(V) Is it severer than before?
a) severer than before b) no change
c) better than before

5. Have you at any time had pain in any part of your body? (1) yes (2) no

If yes, please answer the following questions.

(I) Please fill in the area in the part of your body in which you have had pain.

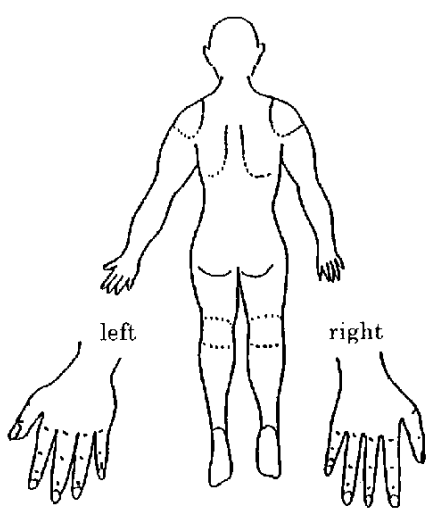

(II) When has it had occurred? (..........years ago)

(III) In which season does it often occur? a) spring b) summer c) fall d) winter e) any time

(IV) When does it often occur during a day?
a) during work b) after work c) in the evening
d) at night e) other (.

(V) How long does the pain continue?
a) a long time b) about one week
c) about one day d) about half a day
e) about several minutes f) a moment

(VT) Is the pain severer than before?
a) severer than before b) no change
c) better than before

6. (cold sensitivity)

7. (general symptoms)

8. (disability in daily life)

9. Have you seen a doctor due to vibration syndromes? (1) yes (2) no

If yes, please answer the following questions.

(I) Where did you see a doctor? (Name of the clinic or hospital)

(II) Which symptoms have you been treated?

(III) How have you been treated?
a) medicine
b) injection c) surgery
d) hot bath e) electric f) massage
g) paraffin $h$ ) other (

(IV) Was it better, after the treatment?

a) better b) no change c) worse 